\title{
Os partidos políticos envolvidos na disputa pelo reconhecimento das famílias homoparentais
}

\author{
Claudio Henrique Miranda Horst ${ }^{1}$ \\ https://orcid.org/0000-0002-2226-4520 \\ ${ }^{1}$ Universidade Federal de Ouro Preto, Instituto de Ciências Sociais Aplicadas, Departamento de Ciências Sociais, Jornalismo e Serviço \\ Social, Mariana, MG, Brasil
}

\section{Os partidos políticos envolvidos na disputa pelo reconhecimento das famílias homoparentais}

Resumo: O objetivo deste artigo é, partindo dos projetos de leis que propunham à aprovação da união civil homoafetiva, analisar o tema à luz dos partidos políticos a que se vinculam seus propositores. Trata-se de uma pesquisa documental envolvendo os projetos de lei que propunham o reconhecimento da união civil homoafetiva, bem como os códigos de ética e as plataformas partidárias dos partidos políticos dos propositores, sendo eles: PT, PR e PSOL. Uma das conclusões aponta à necessidade de os partidos políticos de esquerda pautarem bandeiras de luta em relação à liberdade da orientação sexual e do reconhecimento da diversidade humana vinculadas à totalidade social.

Palavras-chave: Partidos políticos. Famílias homoparentais. Congresso Nacional brasileiro.

\section{Political parties involved in the dispute for recognition of homoparental families}

Abstract: This article aims to analyze the theme of homoparental families based on bills proposed in Brazil to legalize same-sex civil union, particularly looking at the proposing lawmakers' political parties. It is a documentary research involving the bills that proposed the recognition of same-sex civil union, as well as the codes of ethics and the platforms of the political parties: PT, PR and PSOL. One conclusion points to the need for left-wing political parties to play a leading role in the struggles to guarantee freedom of sexual orientation and recognition of human diversity in society as a whole.

Keywords: Political Parties. Homoparental Families. Brazilian National Congress.

Recebido em 18.10.2017. Aprovado em 25.05.2018. Revisado em 13.06.2018.

(C) O(s) Autor(es). 2018 Acesso Aberto Esta obra está licenciada sob os termos da Licença Creative Commons Atribuição-NãoComercial 4.0 Internacional (https://creativecommons.org/licenses/by-nc/4.0/deed.pt_BR), que permite copiar, distribuir e reproduzir em qualquer meio, bem como adaptar, transformar e criar a partir deste material, desde que para fins não comerciais e que você forneça o devido crédito aos autores e a fonte, insira um link para a Licença Creative Commons e indique se mudanças foram feitas. 


\title{
Introdução
}

O combate à LGBTfobia se tornou pauta primordial dentro da luta pelos direitos humanos e ao apontarmos a relação dessa pauta com a luta pelos direitos humanos consideramos que ambas devem ser articuladas com a luta anticapitalista, pois, entendemos que "[...] a legitimação de uma alternativa socialista para a forma capitalista de intercâmbio social não pode ignorar a questão dos direitos humanos”. (MÉSZÁROS, 2008, p. 165).

Nessa direção, é possível reconhecer as estratégias e os limites dessas lutas, tanto para a compreensão dos limites da democracia capitalista quanto para o entendimento que o Estado capitalista é restringido pelas exigências de acumulação do capital, pois " [...] a democracia liberal deixa essencialmente intacta a exploração capitalista, [...]” (WOOD, 2003, p. 233, grifo nosso).

A esquerda, nesse cenário, nas palavras de Wood (2003), deve estabelecer uma política fundamentada na diversidade e na diferença, celebrando e reconhecendo a multiplicidade de lutas emancipatórias no combate às formas de opressão e de exploração. Conforme indica Santos (2017), apesar da sexualidade humana ser própria da individualidade - é no âmbito da individualidade que as experiências se expressam - a mesma deve ter sua análise centrada a partir da totalidade social. Nessa direção, a análise da sexualidade ganha outro norte, que foge as leituras pós-modernas e, ou mesmo, das leituras a partir da centralidade na política ${ }^{1}$.

\begin{abstract}
A análise centrada na política em detrimento da perspectiva de totalidade no entendimento da vida social se destaca no universo das reflexões sobre a organização política da classe trabalhadora e dos movimentos sociais, repercutindo fortemente, também, nas práticas de vários sujeitos políticos e organizações coletivas. Segmentos expressivos da esquerda e da intelectualidade distanciaram, como se fosse possível, a vida cotidiana do sistema do capital. Apanhar as determinações recíprocas entre os complexos sociais da política, do direito, da cultura e a totalidade social tornou-se para estes segmentos algo não apenas desnecessário, mas até equivocado. Sobressai a tendência de autonomizar indivíduos, processos, relações e complexos sociais parciais de suas determinações societárias (SANTOS, 2017, p. 12).
\end{abstract}

Ao demarcarmos o espaço do Congresso Nacional (CN) como mais um dos espaços de luta, e não o único espaço, reforçamos que, para além dos movimentos sociais, a pressão dos partidos de esquerda se torna fundamental para o fortalecimento da luta nesse campo, uma vez que tensionam e exigem propostas condizentes com a garantia dos direitos, em busca de uma sociedade igualitária. Com isso, nas palavras de Coutinho (2006), eles buscam pautas e estratégias de disputa pelo poder que sejam vinculadas à construção de uma nova hegemonia ${ }^{2}$.

Entretanto, no processo de direcionamento para a construção de um novo bloco histórico dessa nova civilização, é o partido que deve se constituir como o espaço-lugar, ou como o organizador da construção de um terreno que dê possibilidades para o desenvolvimento da vontade-coletiva-nacional-popular. Segundo Dias (1996), o partido é, ao mesmo tempo, o organizador e a expressão concreta dessa vontade. Todavia, isso não significa atribuir ao partido nenhuma espécie de responsabilidade exclusiva nesse processo, mas captar sua capacidade de estabelecer direção ao assumir a perspectiva da construção de uma visão de mundo nova e total, que desconstruindo a anterior, mostre-se como o horizonte cuja a nova racionalidade possa se instalar (DIAS, 1996) ${ }^{3}$.

Nesse sentido, cabe problematizar os sujeitos políticos e seus respectivos partidos envolvidos nas propostas, substitutivos, votações e posicionamentos em relação ao reconhecimento das famílias homoparentais. Tudo isso, buscando revelar: os interesses que esses sujeitos representam; o lugar da luta pela diversidade sexual na plataforma de seus partidos e em suas agendas; o tipo de hegemonia que esses atores buscam construir, ou mesmo, legitimar.

Com o pessimismo da razão (não cremos que estejamos no rumo de uma sociedade na qual a opressão vivenciada

\section{É de extrema importância}

para a construção de um novo

bloco histórico, vinculado às

demandas de toda a classe

trabalhadora, a presença de pautas de lutas pela diversidade sexual, que se apresentem de forma una $\mathrm{e}$ diversa no interior dos partidos. Nesse sentido, a pauta pela liberdade de orientação sexual e o reconhecimento da diversidade precisa ser vinculado pelos partidos à estrutura societária. 
pela população LGBT desaparecerá) e o otimismo da vontade (apostamos em espaços de resistência e combate à opressão) é que esse artigo foi urdido. É mister conhecer e utilizar as ferramentas disponíveis para tensionar o Legislativo federal brasileiro.

Neste artigo, inicialmente, refletiremos sobre o CN brasileiro e o papel dos partidos políticos brasileiros, principalmente, em relação às pautas progressistas. Em seguida, apresentaremos os partidos políticos envolvidos na disputa pelo reconhecimento de mais um modelo de família ${ }^{4}$. Por fim, voltaremos às reflexões finais demonstrando os partidos que defenderam a diversidade familiar alinhavado entre a plataforma partidária, o código de ética e os sujeitos filiados ao partido.

\section{Congresso Nacional brasileiro: mapeando contradições}

No cenário de crise estrutural do capital, os direitos humanos vêm sofrendo grandes ofensivas, não há espaços para o aprofundamento dos direitos sociais, que ainda permanecem limitados, estamos " [...] diante da tentativa aberta - infelizmente em grande parte bem sucedida - de eliminar tais direitos, de desconstruir e negar as reformas já conquistadas pelas classes subalternas". (COUTINHO, 2010, p. 37).

Na realidade brasileira dependente, os entraves na luta por direitos se agravam ainda mais, cujo ranço histórico de uma formação sócio-histórica fincada no colonialismo, racismo e patriarcado nunca nos permitiu vivenciar, sequer, a experiência de uma revolução burguesa, conforme a compreensão de Fernandes (2015). Pelo contrário.

O caráter fascista das ações e processos políticos não se funda somente na contradição entre o uso institucionalizado da violência para negar os direitos e as garantias sociais estabelecidas e as imposições 'universais' da ordem legal; mas na existência de uma ordem constitucional que é menos que simbólica ou ritual, pois só tem validade para a autodefesa, o fortalecimento e a predominância dos 'mais iguais' (ou os privilegiados). Por conseguinte, ele se corporifica e atualiza cotidianamente na conexão política, reproduzida constantemente, entre o totalitarismo de classe, a 'salvação nacional' (ou a 'defesa da ordem') por meios autocráticos, reacionários e violentos, e a 'revolução institucional' (ou seja, a dupla ação contrarrevolucionária, que se desdobra simultaneamente, de fato contra a democracia, nominalmente contra o comunismo). (FERNANDES, 2015, p. 40).

Trata-se exatamente de ações e processos políticos de contrarrevolução, que afirmam a totalidade por sua negação, legitimando os interesses das classes dominantes, lógica resultante do padrão de articulação necessária entre o centro e a periferia dependente do mundo capitalista (FERNANDES, 2015). Essa particularidade da formação econômica, política e social é condição determinante para entendermos a relação entre estado, sociedade civil e os impasses na materialização dos direitos sociais.

Nos últimos anos governados pelo Partido dos Trabalhadores (PT) esse cenário se agravou, pois, foi adotada uma política macroeconômica abertamente neoliberal e houve, também, o processo de cooptação de grande parte dos movimentos sociais 5 . É importante sinalizar que o processo de contrarreforma não se caracteriza, apenas, pela ausência de novas medidas, mas também pela "[...] enorme preponderância da conservação (ou mesmo da restauração) em face das eventuais e tímidas novidades". (COUTINHO, 2010, p. 38).

O processo legislativo no interior do CN é constituído por etapas - introdutória, constitutiva e complementar -, onde ocorrem todos os tipos de disputas. Todo esse processo envolve

[...] adesismo oportunista e [...] conservadorismo mais rústico até [...] posições fascistas propriamente ditas; da pretensão 'centrista' e equidistante até as diversas nuanças de esquerda e as posições [...] críticas que tentam - com dificuldade - manter a dignidade da representação popular. (SALDANHA, 1992, p. 88).

Isso porque o legislativo se coloca como uma instituição, que dentro da conjuntura societária é parte integrante de um Estado que a rege - o Estado capitalista - e onde os sujeitos e seus posicionamentos expressam e representam as frações da classe da qual fazem parte, ou vocalizam defesas de outra classe da qual não pertencem.

O cenário político brasileiro tem demonstrado o esforço - ou o modo de como tem se dado o exercício da hegemonia - que alguns grupos têm realizado, no sentido de organizar no interno do Legislativo federal, espaços como as frentes parlamentares, que buscam concretizar na vida pública os interesses desses grupos hegemônicos a partir das leis, das políticas, dos vetos e das campanhas.

A bancada do Boi, da Bala e da Bíblia (BBB) é um exemplo concreto de como esses grupos fundamentalistas vêm realizando alianças quando se trata de discussões de cunho conservador ${ }^{6}$. Apesar do 
aparente interesse distinto, em certas ocasiões, como a votação do código florestal e a demarcação das terras indígenas, a bancada do Boi conseguiu apoio da bancada da Bíblia e da Bala. Em outro momento, as mesmas bancadas apoiaram a discussão que a bancada da Bíblia defendeu em torno do Estatuto da Família e, posteriormente, ambas defenderam os retrocessos no Estatuto do Desarmamento, dirigido pela bancada da Bala. Segundo a Deputada Erika Kokay (PT/DF) essas ações demonstram que "[...] na verdade, todos eles compartilham da mesma ideologia, unem-se na defesa da sociedade patrimonialista e patriarcal" (MARTINS, 2015, grifo nosso) e combinam em suas ações força e consenso.

Entretanto, não há só um esforço moral de falar em nome da sociedade, da vontade coletiva - muitas vezes pelo simples interesse eleitoreiro. Esse processo vem permitindo que esses grupos dialoguem com o discurso do senso comum, colocando-se como representantes do povo. Esse esforço demonstra o que Gramsci dizia sobre a necessidade da construção da hegemonia que, por um lado, deve se constituir como vontade coletiva e, por outro, autogoverno. No sentido gramsciano, o autogoverno não mantém os grupos subalternos no plano inferior, ao contrário, elevam e os tornam mais capazes de refletir e dominar as situações, a partir disso, vão realizando o que o autor chamou de reforma intelectual moral. (SIMIONATTO, 1997; COUTINHO, 2006).

O projeto político em voga, direcionado para a ordem econômica, permite que o Estado seja um forte potencial de cooptação e supremacia, o que provoca no campo ideológico a despolitização das classes subalternas. Essa prática está presente no atual Congresso Brasileiro, considerado como o mais retrógado e conservador desde a ditadura militar (DEPARTAMENTO INTERSINDICAL DE ASSESSORIA PARLAMENTAR, 2015). Tais práticas no interior do atual CN claramente “[...] conservadora[s], antidemocrática[s] e excludente[s], leva a burguesia a fazer e refazer suas alianças, a romper os elos que unem as classes e seus dirigentes, tornando-os cúmplices da dominação burguesa e cerceando as possibilidades de formação de organizações revolucionárias". (SIMIONATTO, 1997). Ou seja, a luta de classes não vem sendo travada mais em nome da conquista de novos direitos, mas, sim, na defesa daqueles poucos que já foram conquistados (COUTINHO, 2010), e que estão sendo gradualmente destruídos.

O CN é constituído por uma diversidade de projetos que compõem práticas sociais voltadas para a construção - ou permanência - de uma hegemonia. A direção disputada no interior do legislativo é diversa, cabe ressaltar que num primeiro olhar dependendo da pauta em debate, não é possível identificar a que frações de classe as defesas das frentes parlamentares e comissões pertencem ideologicamente. É possível identificar pautas progressistas apoiadas por membros ligados a bancadas que se apresentam como conservadoras, porém, sem a defesa da transformação da sociedade. Cabe aqui a reflexão de Togliatti (1954, p. 25, grifo nosso) que, ao ressaltar a luta por justiça e democracia, reafirmava que

Todos os direitos são afirmados, mas o exercício de qualquer direito pode ser negado, e é negado, de fato, a quem não se encontra em determinadas condições materiais e sociais, e qualquer direito é destruído, de propósito, quando o curso dos acontecimentos é tal que ponha em risco a segurança de determinado grupo dominante.

No interior desse espaço de disputa que tem sido possível aos partidos, sindicatos, associações profissionais, movimentos sociais, sujeitos organizados desempenharem papel fundamental nas relações entre Estado/ sociedade, o que diminui, ou, pelo menos, há um esforço nessa direção, para controlar os poderes coercitivos do Estado capitalista. No interior do $\mathrm{CN}$ as disputas dessas diversas organizações e entidades contribuem para "[...] o alargamento da participação nos processos decisórios e o bloqueamento das estratégias de destruição dos direitos sociais e dos institutos de representação coletiva [...]" (SIMIONATTO, 1997) ainda que o cenário não se apresente favorável, principalmente, para as pautas relacionadas ao movimento LGBT.

Nesse cenário, as diversas lutas como a da população LGBT vêm se restringindo às reformas pontuais, desvinculadas de um projeto, em consonância com a totalidade da vida social, o que delimita a possibilidade dessas lutas. As demandas pontuais, ainda que importantes, nas palavras de Simionatto (1997), "“...] hipertrofiamse em um turbilhão de demandas fragmentadas, facilmente despolitizadas e burocratizadas pelo próprio Estado [...]". Definida por Gramsci como pequena política, essas lutas envolvem questões parciais e do cotidiano, e que precisam se vincular com a grande política, visando ao estabelecimento de novas relações.

A grande política compreende questões ligadas à fundação de novos Estados, à luta pela destruição, pela defesa, pela conservação de determinadas estruturas orgânicas econômico-sociais. A pequena política compreende as questões parciais e cotidianas que se apresentam no interior de uma estrutura já estabelecida em decorrência da lutas pela predominância entre as diversas frações de uma mesma classe política. (GRAMSCI, 2002, p. 21). 
Essa direção, nas palavras de Simionatto (1997), expressa o esmaecimento das lutas de dimensão global, cuja elite intencionalmente busca reforçar e reduzir como se fossem questões meramente particulares e desvinculadas da totalidade social. Em outras palavras, é necessário um esforço na direção de um grupo político que, a partir da disputa no interior da sociedade civil, busque reafirmar "A relação dialética entre social e político, político e econômico, Estado e sociedade, público e privado, [...] enraizando práticas sociais que possibilitem estabelecer novas contratualidades na dinâmica societária”. (SIMIONATTO, 1997).

É de extrema importância para a construção de um novo bloco histórico, vinculado às demandas de toda a classe trabalhadora, a presença de pautas de lutas pela diversidade sexual, que se apresentem de forma una e diversa no interior dos partidos. Nesse sentido, a pauta pela liberdade de orientação sexual e o reconhecimento da diversidade precisa ser vinculado pelos partidos à estrutura societária.

Optamos, assim, pela discussão em torno dos partidos que propuseram projetos de lei que se encontram em tramitação, visto que há possibilidade de disputas e mudanças em aberto, já que durante a tramitação os projetos estão sujeitos a todo tipo de encaminhamento. Sendo os seguintes projetos do presente estudo: Projeto de Lei (PL) 580/2007 (e apensado a ele PL 4914/2009; PL 5120/2013) (BRASIL, 2007) e o Projeto de Lei do Senado (PLS) 612/2011 (BRASIL, 2011).

\section{Os projetos de lei, os partidos políticos e a pauta das uniões homoafetivas}

Os sujeitos proponentes dos projetos que ainda se encontram em trâmite, são: Clodovil Hernandes apensados José Genoíno; Jean Wyllys e Erika Kokay - e Marta Suplicy. Respectivamente, os partidos que propuseram o reconhecimento das uniões homoafetivas, por meio desses autores, foram: Partido da República (PR), Partidos dos Trabalhadores (PT) e o Partido Socialismo e Liberdade (PSOL). Ao escolhermos a discussão por um projeto ainda em tramitação é notável que aqui não estamos tratando apenas de partidos de esquerda.

\section{O Partido dos Trabalhadores e a pauta pela liberdade de orientação sexual}

Historicamente o PT foi o primeiro partido a pautar no seu plano de governo as demandas do movimento LGBT, nas eleições em que Lula concorreu à presidência de 1994. Porém, com a ameaça da retirada do apoio por parte da Igreja Católica, essas demandas foram retiradas do programa (MELLO, 2005).

Também foi por meio da Deputada Federal Marta Suplicy que o PT colocou no centro do debate, em 1995, pela primeira vez o reconhecimento das uniões entre pessoas do mesmo sexo. Esse fato demonstra não apenas um posicionamento particular dos seus membros, mas que o partido veio reconhecendo, ao longo dos anos, que a classe trabalhadora é una e diversa. Portanto, a diversidade sexual se faz parte integrante dessa classe. Contudo, historicamente esses posicionamentos foram motivados por pressões no interior do partido.

A atenção que o PT concede às políticas de identidade não reflete processos de internalização do conjunto da militância nem do quadro dirigente, constituindo-se resultado da pressão e da disputa ideológica que militantes petistas, que também são gays e lésbicas, fazem tensionando o partido para a aceitação e defesa da liberdade de orientação sexual. (SANTOS, 2005, p. 258).

Nessa direção, a autora demonstra que, embora a luta dos outros sujeitos políticos fosse reconhecida pelo partido, ela ainda se apresentava como algo pulverizado e fragmentado, tornando competência de setoriais responsáveis pelo debate da opressão. Em 2003, o partido realizou o Encontro Nacional LGBT do PT, onde se discutiu novas estratégias e formas de enfrentamento da opressão pelo partido, especificamente, no direcionamento da militância e na atuação política. Santos (2005), ao analisar o entendimento e o direcionamento do PT na luta pela liberdade de orientação sexual até meados de 2000, conclui.

No âmbito do PT, verificamos duas tendências principais: (1) defesa da liberdade de orientação sexual restrita ao universo da luta pela igualdade de oportunidades e da realização dos direitos humanos, sem, no entanto, aprofundar as causas da discriminação e sua relação com a sociabilidade vigente. Deposita-se, assim, na aprovação das leis enorme expectativa quanto à resolução da opressão e (2) uma tendência minoritária, ainda com falas e intervenções isoladas, mas que sinaliza que o enfrentamento das formas opressivas e, em particular, da homofobia só é possível no âmbito daquilo que Hobsbawn (1996) advertiu: a defesa das políticas de identidade só tem sentido se referida à humanidade [...] (SANTOS, 2005, p. 262). 
O PLS 612/20117 (BRASIL, 2011) que se encontra em tramitação foi proposto pela Senadora Marta Suplicy, atualmente vinculada ao PMDB. Ao longo dos seus mandatos e militância política vem defendendo a pauta LGBT, sempre que coube o posicionamento dentro do legislativo federal. A primeira vez que se discutiu no $\mathrm{CN}$ as conjugalidades homossexuais, a diversidade sexual e os direitos dessa população, foi por conta da apresentação do PL 1151/1995 (BRASIL, 1995), cuja a autoria é dessa senadora, o projeto buscou reconhecer a parceria civil registrada entre pessoas do mesmo sexo.

Proposto por um deputado do PT, o PL 4914/2009 (BRASIL, 2009) encontra-se apensado ao PL 580/ 2007 (BRASIL, 2007) que está em trâmite. Esse projeto partiu da autoria de José Genoíno (PT/SP), mas, também, foi proposto em conjunto com outros deputados. José Genoíno integrou a Comissão Especial do PL 1151/1995, que disciplina a União Civil entre Pessoas do Mesmo Sexo como suplente.

Outra deputada propositora do PL 5120/2013 (BRASIL, 2013) pelo PT é Erika Kokay. Dentre as diversas comissões que participou e, ainda integra, cabe destacar entre as Comissões Permanentes: a Comissão de Direitos Humanos e Minorias e a Comissão de Seguridade Social e Família. Participa, também, da Comissão Especial do PL 6583/2013, o Estatuto da Família (BRASIL, 2013).

A proposição de um projeto que reconhece mais um modelo de arranjo como família é posto como algo orgânico às suas legislaturas, resultante de enfrentamentos e de lutas contra qualquer tipo de preconceito. Os posicionamentos dos deputados citados, apesar de terem como princípio uma experiência pessoal e de visão de mundo - a partir da militância e diálogo com os movimentos sociais - também se encontram atrelados a defesa realizada pelo partido a que pertencem.

A partir da leitura do Estatuto do Partido dos Trabalhadores disponível no site oficial é possível identificar em seu art. 14 que são deveres do filiado ou da filiada: "II - combater todas as manifestações de discriminação em relação à etnia, aos portadores e às portadoras de deficiência física, aos idosos e às idosas, assim como qualquer outra forma de discriminação social, de gênero, de orientação sexual, de cor ou raça, idade ou religião; [...]” (PARTIDO DOS TRABALHADORES, 2015, p. 6, grifo nosso).

No código de ética do partido também aparece como princípio ético fundamental, devendo orientar a conduta de todos os filiados ao PT: "III - o dever de combater, por todos os meios ao seu alcance, a exclusão social, a desigualdade, e quaisquer formas de discriminação quanto ao sexo, à raça, à etnia, à religião, à condição econômica, à atividade profissional, às convicções políticas, a qualquer condição de deficiência, de idade, de orientação sexual, bem como os atos de assédio moral, sexual, a pedofilia, a violência doméstica e outros da mesma natureza". (PARTIDO DOS TRABALHADORES, 2009, p. 5, grifo nosso). Comparece, também, em outro momento do documento, como deveres éticos dos filiados "IV - combater permanentemente manifestações discriminatórias em relação à etnia, à deficiência física, a condições sociais, de gênero, de orientação sexual, de cor, de raça, de idade ou de religião". (PARTIDO DOS TRABALHADORES, 2009, p. 10, grifo nosso).

Além da defesa citada entre os princípios fundamentais do PT, outro ponto que cabe destacar é que o partido possui um setorial LGBT criado em 1992, sendo o primeiro núcleo LGBT de um partido político no Brasil. Recentemente quando a atual Presidenta Dilma cedeu à bancada evangélica e vetou o material sobre diversidade sexual para as escolas, o setorial publicou uma nota pública defendendo que o PT permanecesse na defesa de uma bandeira que sempre levantou e que a presidenta voltasse atrás com a decisão, o que não ocorreu.

Como bem elucidado por Coutinho (2006), o papel de um partido deve ser sempre de universalizar as demandas postas pelos diversos movimentos e segmentos da sociedade, abarcando ao máximo as vontades coletivas. E, apesar do PT ter sido criado com base na ideia da transformação social, ligada a bandeira socialista e aos movimentos sociais, concordamos com Menegat (2017, p. 13), quando o autor aponta:

Se se pode dizer que o PT um dia teve um programa, esta foi a sua natureza: um modo de governar que tinha na intenção do socialismo o papel de um tipo ideal de modernização a ser concluída por meio de políticas públicas, apesar de cada vez mais inviabilizadas pela violência da crise e dos acontecimentos mundiais. Por hora, observe o(a) leitor(a) que a densidade da crítica ao capitalismo nestas formulações se concentra basicamente no seu modo de ser, nunca na negação de seus fundamentos constitutivos.

\section{Partido da República: a voz dissonante}

Quando fazia parte do Partido da República, o então deputado federal Clodovil Hernandes propôs o PL 580/2007 (BRASIL, 2007). Exerceu seu mandato como deputado federal na legislatura entre 2007-2011 - falecendo em 2009, anteriormente ao PR, foi filiado ao Partido Trabalhista Cristão (PTC), participou da Comissão Permanente de Direitos Humanos e Minorias e Seguridade Social e Família. Tratava-se de um deputado declaradamente homossexual, porém, em sua curta legislatura, foi a única pauta defendida pelo 
movimento LGBT que o mesmo apresentou.

Em relação ao partido, não há no Estatuto do Partido da República qualquer menção ao combate à opressão/exploração por orientação sexual, identidade de gênero ou pela igualdade entre sexos. No código de ética do partido também não foi encontrado nenhum artigo que se refira à temática do combate às opressões. Já no programa do partido é encontrado um tópico intitulado "Minorias", onde fica definido que o PR "[...] defende o direito das minorias étnicas, sociais e religiosas, de plena participação na vida social" (PARTIDO DA REPÚBLICA, 2016), reforçando, posteriormente, que a legislação deve propiciar proteção e benefícios aos negros, pelo passado histórico e proteção estatal aos índios, afim de que sejam garantidos seus direitos e suas tradições.

No tópico sobre as mulheres, defendem alterações legislativas necessárias para que se assegure uma rigorosa igualdade de direitos na sociedade, devendo ser protegidas, principalmente, as mães solteiras. Também há uma defesa em torno dos direitos dos idosos, devendo sempre garantir-lhes, por meio das legislações, seus direitos (PARTIDO DA REPÚBLICA, 2016).

A justificativa do projeto, se baseia na tendência mundial em aprovar o casamento entre pessoas do mesmo sexo e a importância de integrar à população LGBT os direitos visando à eliminação de preconceitos.

Fica claro, portanto, que o partido não pauta a questão dos direitos da população LGBT, o que nos possibilita pensarmos que o PL apresentado pelo Deputado Clodovil diz respeito mais a uma causa própria - no sentido da sua relação com o partido - devido a sua orientação sexual, do que uma pauta apontada e defendida pelo partido.

\section{O Partido Socialismo e Liberdade e a defesa pelo socialismo com liberdade.}

O PL 5120/2013 (BRASIL, 2013) foi proposto pelo deputado Jean Wyllys. O deputado reforça em seus pronunciamentos ser o único deputado assumidamente homossexual e isso faz uma grande diferença, uma que demonstra representatividade por um segmento. Nesse sentido, desde o primeiro mandato vem se posicionamento em nome das ditas minorias e dos segmentos que mais sofrem na realidade brasileira. Fato que pode ser observado tanto pelas comissões que compõe, tanto pelos projetos de lei que vem propondo ao longo dos anos.

Tal posicionamento está diretamente articulado com os documentos oficiais do partido. No Estatuto do PSOL há uma determinação para a criação de setoriais no interior do partido "[...] tais como a da mulher, do movimento negro, dos homossexuais, dos indígenas, dos estudantes, do movimento sindical, e todos aqueles que possam ser incluídos pelo Partido [...]" (PARTIDO SOCIALISMO E LIBERDADE, 2010, grifo nosso). Também comparece como determinação em seu capítulo II, art. $5^{\circ}$

O Partido SOCIALISMO E LIBERDADE desenvolverá ações com o objetivo de organizar e construir, junto com os trabalhadores do campo e da cidade, de todos os setores explorados, excluídos e oprimidos, bem como os estudantes, os pequenos produtores rurais e urbanos, a clareza acerca da necessidade histórica da construção de uma sociedade socialista, com ampla democracia para os trabalhadores, que assegure a liberdade de expressão política, cultural, artística, racial, sexual e religiosa, tal como está expresso no programa partidário. (PARTIDOS SOCIALISMO E LIBERDADE, 2010, grifo nosso).

No documento do partido a construção de uma nova sociedade justa, igualitária e fraterna só ocorrerá se construída junto as lutas das minorias.

No Programa Partidário do PSOL há um tópico intitulado "Pela Livre Expressão Sexual", onde o partido define seu posicionamento:

A luta pelo direito a livre orientação sexual é uma luta nossa. As mobilizações de centenas de milhares de pessoas em todo o país durante as chamadas paradas gays, com algumas marchas chegando a quase um milhão de pessoas, mostra o claro avanço da luta pelos direitos civis. Contra toda e qualquer violência e preconceito contra a orientação sexual dos LGBT. Pelo reconhecimento da união patrimonial de pessoas do mesmo sexo e suas decorrências legais! Com estes princípios defendidos por todo o partido, os movimentos dos LGBT construirão também o programa partidário sobre o tema. (PARTIDO SOCIALISMO E LIBERDADE, [2004], grifo nosso).

Segundo Coutinho (2006), enquanto os movimentos sociais colocam na agenda as questões mais decisivas, quase sempre particulares, a tarefa dos partidos políticos seria universalizar essas demandas provindas dos diferentes setores da sociedade, ou seja, "[...] um partido que se pretende revolucionário tem de se colocar como criador de uma vontade coletiva transformadora, de uma vontade universal. Gramsci diria: de uma 
vontade coletiva nacional popular" (COUTINHO, 2006, p. 116), que represente a todas(os) e que, a nosso ver, somente o PSOL, no atual cenário, é que se aproxima de tal esforço e tem apresentado um direcionamento coerente entre o que determina o partido e o posicionamento de seus integrantes no interior do $\mathrm{CN}$.

As diversas propostas apresentadas ao longo da história - 1995 a 2013 - diferenciavam-se umas das outras por questões importantes. Podemos considerar que o PL 5120/2013 (BRASIL, 2013) se apresenta como algo que representa grande parte da população LGBT - visto que, na sua diversidade interna, talvez seja impossível algo que, nessa sociedade, se materialize como proposta que representa a todos - ao defender os mesmos nomes com os mesmos direitos o projeto de Jean Wyllys (PSOL) e de Erika Kokay (PT) vocalizaram que as demandas dessa população não podem ser vistas como favores, ajuda ou, até mesmo, garantido como algo diferente, como foi pensando em outra resolução, especialmente, ao tratar da parceria civil registrada entre pessoas do mesmo sexo. Tratou-se de defender uma igualdade, pelo menos no formato da lei, sem diferenças pela orientação sexual.

\section{Considerações finais}

Nosso percurso no presente texto foi analisar a pauta pelo reconhecimento das famílias homoparentais à luz dos partidos políticos a que se vinculam seus propositores. É importante sinalizar que fizemos a opção pelos projetos de lei que ainda estão em tramitação. Além disso, chamamos atenção à temporalidade dos projetos que foram apresentados em momentos diferentes. Nessa direção, cabe ressaltar, também, que a composição do CN se modificou ao longo dos anos, bem como a bancada de cada partido e seus representantes. Entretanto, não foram perdidas as características do espaço em si e as contradições que o permeiam.

Os poucos avanços conquistados pelo movimento LGBT se deram num cenário conservador que tem se ampliado - vide a composição do $\mathrm{CN}$ mais conservadora desde a ditadura militar brasileira. Isso, porque, como demonstrou Coutinho (2006, p. 21), “[...] esse processo de progressiva democratização, de socialização da política, choca-se com a apropriação privada dos mecanismos de poder". Contudo, o movimento LGBT se torna essencial nesse cenário.

As práticas políticas do universo LGBT são importantes porque rompem o silêncio; promovem a auto-organização política dos indivíduos e sinalizam questões e desafios que precisam de resposta. Fazem eclodir as tensões quando denunciam o conservadorismo, que se apresenta em diferentes ambientes institucionais e pessoais, revelando-se funcional ao sistema de reprodução do capital. (SANTOS, 2017, p. 17).

Como já imaginávamos na defesa da presente pauta, não foi possível uma divisão nítida entre partidos de esquerda e de direita. Visto que, desde a formulação de certas proposições até o momento de votação, os partidos e sujeitos políticos favoráveis pertenciam aos mais diversos partidos. Todavia, isso não nos impediu de reconhecer a importância de alguns partidos no debate sobre as famílias e a diversidade sexual.

Consideramos que o PT exerceu papel fundamental, uma vez que majoritariamente todas as pautas consideradas por nós como progressistas foram propostas por candidatos desse partido. Tal ocorrência, demonstra uma ligação direta entre a plataforma do partido e seus deputados, em que ambos defendem uma sociedade plural e democrática, ainda que não apareça a luta LGBT atrelada à luta anticapitalista.

Fato diferentemente ocorrido com o PR, cuja plataforma partidária em nada diz respeito às pautas progressistas, mas, sim pelo contrário, pontuam questões conservadoras, demonstrando que a proposta do deputado Clodovil diz respeito a uma pauta do deputado, e, não, às defesas do partido.

Outro partido que demarca seu espaço nessa luta é o PSOL. Além de seus deputados demonstrarem uma consonância com o que o partido defende, também, é notável em alguns discursos os limites desses avanços no capitalismo.

A presença dos partidos que pautem as lutas LGBTs, principalmente, atrelado à luta anticapitalista é algo fundamental num cenário democrático. Contudo, não podemos perder de vista que mudanças legais não produzem imediatamente e obrigatoriamente mudanças nas vidas dos sujeitos, principalmente, em uma sociedade de classes, com particularidades como a sociedade brasileira.

Diante do exposto, apesar das expectativas não se mostrarem favoráveis para a construção de uma contra hegemonia na discussão sobre famílias e sexualidades, é preciso, cotidianamente, denunciar esta ordem societária enquanto reprodutora de preconceitos que "[...] obstaculiza o desenvolvimento da individualidade, ceifa descobertas e encontra modos contínuos de assegurar sua reprodução". (SANTOS, 2017, p.15, grifo nosso). Visando, em longo prazo, "[...] agregar vontades coletivas na defesa de projetos alternativos ao projeto dos dominantes". (SIMIONATTO; COSTA, 2012, p. 235, grifo nosso). 


\section{Referências}

BRASIL. Lei n ${ }^{\circ}$ 10.406, de 10 de janeiro de 2002. Institui o Código Civil. Diário Oficial da União, Brasília, DF, 11 jan. 2002. Disponível em: <http://www.planalto.gov.br/ccivil_03/leis/2002/110406.htm>. Acesso em: 21 mar. 2016.

. Câmara dos Deputados. Projeto de Lei n ${ }^{\circ}$ 580/2007. Altera a Lei no 10.406, de 10 de janeiro de 2002 - Código Civil, para dispor sobre o contrato civil de união homoafetiva. 2007. Disponível em: <http://www.camara.gov.br/proposicoesWeb/ fichadetramitacao?idProposicao=346155> . Acesso em: 21 mar. 2016.

Câmara dos Deputados. Projeto de Lei no 4914/2009. Altera a Lei no 10.406, de 10 de janeiro de 2002 - Código Civil. 2009.

Disponível em: <http://www.camara.gov.br/proposicoesWeb/fichadetramitacao?idProposicao=427692>. Acesso em: 21 mar. 2016.

. Câmara dos Deputados. Projeto de Lei n ${ }^{\circ} 5120 / 2013$. Altera os arts. 551, 1.514, 1.517, 1.535, 1.541, 1.565, 1.567, 1.598, 1.642,

1.723 e 1.727 da Lei no 10.406 de 10 de janeiro de 2002, para reconhecer o casamento civil e a união estável entre pessoas do mesmo sexo.

2013. Disponível em:<http://www.camara.gov.br/proposicoesWeb/fichadetramitacao?idProposicao=567021>. Acesso em: 21 mar. 2016.

Câmara dos Deputados. Projeto de Lei $n^{\circ} 1151 / 1995$. Disciplina a união civil entre pessoas do mesmo sexo e dá outras providências.1995. Disponível em: <http://www.camara.gov.br/proposicoesWeb/fichadetramitacao?idProposicao=16329>. Acesso em: Acesso em: 21 mar. 2016.

Câmara dos Deputados. Projeto de Lei no 6583/2013. Dispõe sobre o Estatuto da Família e dá outras providências. 2013.

Disponível em: <http://www.camara.gov.br/proposicoesWeb/fichadetramitacao?idProposicao=597005>. Acesso em: 21 mar. 2016.

. Senado Federal. Projeto de Lei do Senado no 612, de 2011. Altera os arts. 1.723 e 1.726 do Código Civil, para permitir o

reconhecimento legal da união estável entre pessoas do mesmo sexo. 2011. Disponível em: $<$ https://www25.senado.leg.br/web/atividade/ materias/-/materia/102589>. Acesso em: 21 mar. 2016.

COUTINHO, C. N. Intervenções: o marxismo na batalha das ideias. São Paulo: Cortez, 2006.

. A Hegemonia da Pequena Política. In: OliVeIRA, F; BRAGA, R; RIZEK, C. (Org.). Hegemonia às Avessas: economia, política e cultura na era da servidão financeira. São Paulo: Boitempo, 2010.

DEPARTAMENTO INTERSINDICAL DE ASSESSORIA PARLAMENTAR. Radiografia do novo Congresso: legislatura 20152019. Brasília, 2014.

DIAS, E. F. Cidadania e racionalidade de classe. Universidade e Sociedade, São Paulo, ano 6, n. 11, jun. 1996.

FERNANDES, F. Poder e contrapoder na América Latina. 2. ed. São Paulo: Expressão Popular, 2015.

GRAMSCI, A. Cadernos do cárcere. 3. ed. Rio de Janeiro: Civilização Brasileira, 2002. 3 v.

LIMA, K. Brasil em tempos de contrarrevolução. Universidade e Sociedade, Brasília, ano 27, n. 59, p. 92-103, jan. 2017.

MARTINS, R. A bancada BBB domina o congresso. Carta Capital, São Paulo, 14 abr. 2015. Disponível em: <http:// www.cartacapital.com.br/revista/844/bbb-no-congresso-1092.html>. Acesso em: 30 set. 2015.

MELLO, L. Novas famílias: conjugalidade homossexual no Brasil contemporâneo. Rio de Janeiro: Garamond, 2005. (Coleção Sexualidade, Gênero e Sociedade).

MENEGAT, M. Feitiço de fundo de quintal - o PT, a crise e a economia política da barbárie. Metaxy, Rio de Janeiro, v. 1, n. 1, p. 9-27, mar. 2017.

MÉSZÁROS, I. Para além do capital: rumo a uma teoria da transição. São Paulo: Boitempo, 2002.

. Filosofia, ideologia e ciência social. São Paulo: Boitempo, 2008.

PARTIDO DA REPÚBLICA. Programa do Partido da República. 2016. Disponível em: <http://www.partidodarepublica.org.br/ partido/doutrina.html>. Acesso em: 21 mar. 2016.

PARTIDO DOS TRABALHADORES. Código de ética e disciplina do Partido dos Trabalhadores. 2009. Disponível em: <http:// www.pt.org.br/wp-content/uploads/2014/03/codigodeetica.pdf>. Acesso em: 21 mar. 2016.

PARTIDO DOS TRABALHADORES. Estatuto do Partido dos Trabalhadores. 2015. Disponível em: <http://www.pt.org.br/wpcontent/uploads/2016/03/ESTATUTO-PT-2012-VERSAO-FINAL-alterada-outubro-de-2015-2016mar22.pdf>.Acessoem: 21 mar. 2016. PARTIDO SOCIALISMO E LIBERDADE. Estatuto do Partido Socialismo e Liberdade. 2010. Disponível em: <http:// www.psol50.org.br/partido/estatuto/>. Acesso em: 21 mar. 2016. Não paginado.

. Programa do Partido Socialismo e Liberdade. [2004]. Disponível em: <http://www.psol50.org.br/partido/programa/>. Acesso em: 21 mar. 2016. Não paginado.

SALDANHA, N. O que é o Poder Legislativo. 5. ed. São Paulo: Brasiliense, 1992. (Coleção Primeiros Passos).

SANTOS, S. M. de M. Diversidade sexual: fonte de opressão e de liberdade no capitalismo. Argumentum, Vitória, v. 9, n. 1, p. 8-20, jan./ abr. 2017.

. O pensamento da esquerda e a política de identidade: as particularidades da luta pela liberdade de orientação sexual. 2005. 333 f. Tese (Doutorado em Serviço Social) - Programa de Pós-Graduação em Serviço Social, Universidade Federal Pernambuco, Recife, 2005. SIMIONATTO, I. O social e o político no pensamento de Gramsci. Gramsci e o Brasil, 1997. Disponível em: <https://www.acessa.com/ gramsci/?page=visualizar\&id=294>. Acesso em: 25 nov. 2015. Não paginado.

; COSTA, C. R. Como os dominantes dominam: o caso da bancada ruralista. Temporalis, Brasília, DF, ano 12, n. 24, p. 215-237, jul./dez. 2012.

WOOD, E. M. Democracia contra capitalismo: a renovação do materialismo histórico. São Paulo: Boitempo, 2003. 


\section{Notas}

1 "Os principais problemas que assinalamos a partir dos fundamentos politicistas que incidem no tema da diversidade são: [1)] perda do referencial ontológico-histórico, da centralidade do trabalho na vida social; [2)] desconsideração das mudanças ocorridas na produção da vida material mediante a crise estrutural do capital e as implicações e desdobramentos na vida cotidiana e na subjetividade dos indivíduos; [3)] fixação na luta eleitoral para a conquista do poder político do Estado e suas instituições em detrimento da valorização das lutas sociais; [4)] apologia do parlamento como espaço de resolução das violações de direitos e formas de opressão; [5)] consagração da igualdade de oportunidade e judicialização das reivindicações como meta que deve ser alcançada por mulheres, LGBT; população negra e demais sujeitos que sofrem violação de direitos a partir do extravio de sua diversidade.” (SANTOS, 2017, p. 12-13, grifo nosso).

2 Segundo Gramsci (2002) uma relação de hegemonia é estabelecida quando um conjunto de crenças e valores se enraíza no senso comum, muitas vezes sem plena consciência e que passa a orientar a ação de grandes massas de mulheres e homens. Ou seja, em nosso tema trata-se de aceitar a família nuclear burguesa patriarcal e a orientação heterossexual como norma única.

3 É importante destacar que no presente texto a análise contempla partidos políticos parlamentares, e conforme nos chama atenção Dias (1996), a concepção de partido trabalhada por Gramsci se difere profundamente da modalidade dos partidos de caráter parlamentar.

4 Nosso direcionamento ao defender o reconhecimento da família homoparental parte da compreensão que os sujeitos vivenciam questões no cotidiano que podem ser sanadas a partir dessa conquista, por exemplo, questões relacionadas ao acesso à seguridade social. Ao mesmo tempo, não temos a pretensão de considerar que tal modelo de família confronta a lógica capitalista por si só. Para nós, a crítica necessária à instituição familiar não pode se limitar à defesa da diversidade de modelos. Pelo contrário, somente em outra sociabilidade, que não a do capital, essa instituição deixará de cumprir seu papel de perpetuação e internalização do sistema de valores dominantes, totalmente opostos à verdadeira igualdade, conforme nos lembra Mészáros (2002). Por isso, a necessidade se superá-la sobre as determinações capitalistas, independente do seu formato.

5 Trata-se de um momento histórico nas palavras de Lima (2017,p. 93), de “[...] aburguesamento da referida burocracia partidária e sindical da classe trabalhadora que substitui na sua pauta de ação política a 'revolução contra a ordem' pela 'ocupação do poder', através da coalizão de classes, consubstanciando um novo 'acordo pelo alto' na história brasileira, demarcando o período de 2003 a 2016”. Elemento importante para se pensar a pauta aqui discutida, foi o veto do Kit Escola sem Homofobia, e a retirada do termo gênero do Plano Nacional de Educação, ambos realizados pela ex-presidente Dilma.

6 "Esta composição política entre setores conservadores, acomodando, inclusive, os interesses mais arcaicos de determinadas frações de classe e a exclusão ou a busca do consenso passivo e/ou ativo dos trabalhadores, também não constitui fenômenos historicamente datados, mas é característica inerente à natureza das burguesias dos países capitalistas.” (LIMA, 2017, p. 95).

7 Altera a redação do art. 1.723 da Lei 10.406/02 (BRASIL, 2012) para reconhecer como entidade familiar a união estável entre duas pessoas, configurada na convivência pública, contínua e duradoura e estabelecida com o objetivo de constituição de família.

\section{Claudio Henrique Miranda Horst}

claudiovasques1@hotmail.com

Doutorado em Serviço Social pela Universidade Federal de Santa Catarina (UFSC)

Professor do Departamento de Ciências Sociais, Jornalismo e Serviço Social da Universidade Federal de Ouro Preto (UFOP)

\section{UFOP}

Instituto de Ciências Sociais Aplicadas

Rua do Catete, 166 - Centro

Mariana - Minas Gerais - Brasil

CEP: $35.420-000$

\section{Agência financiadora \\ Não se aplica.}

Contribuições dos autores

Não se aplica.

Aprovação por Comitê de Ética e consentimento para participação

Não se aplica.

\section{Consentimento para publicação}

Não se aplica.

\section{Conflito de interesses}

Não há conflito de interesses. 